\title{
El cooperativismo de consumo: orígenes y actualidad
}

\author{
Dr. Javier Divar Garteiz-Aurrecoa \\ Universidad de Deusto
}

Recibido: $\quad$ 03.05.11

Aceptado: 26.05.11

Resumen: Los estatutos de la Cooperativa de Consumo de los Probos Pioneros de Rochdale, en 1844, marcan el inicio de los llamados principios cooperativos, que han venido sirviendo, actualizados por la Alianza Cooperativa Internacional, para delimitar los caracteres jurídicos de las sociedades cooperativas. Sin embargo, la legislación de cooperativas debe determinar, en cada caso, expresamente, los caracteres que delimitan la naturaleza jurídica de estas sociedades, basándose en precisiones jurídicas y sin atender a inseguros enunciados históricos, generalistas y filosóficos.

Palabras clave: Cooperativismo, Consumo, Principios, Legislación.

Abstract: Updated by the International Co-operative Alliance, the by laws of the Rochdale Society of Equitable Pioneers (1884) marked the beginning of cooperative principles which have been used to define the legal nature of cooperative companies. However, legislation on cooperatives must expressly set down in each case the characteristics that define the legal nature of these companies, based on judicial interpretation, without taking into account historical, generalist and philosophical assertions.

Key words: Cooperativism, Consumption, Principles, legislation. 
Es muy conocida por su impacto doctrinal la formulación que respecto al poder de los consumidores hizo Charles Gide, profesor en la Sorbona y miembro de la llamada Escuela de Nimes, a principios del siglo $x x^{1}$, sobre el inmediato futuro económico del «reinado del consumidor».

En el momento presente, el consumismo es tan vital para el orden económico que se ha llegado a decir, con exagerada intención, que en el mundo actual es más importante ser consumidor que ser ciudadano, puesto que la condición de consumidor en las sociedades avanzadas es un bien jurídico de especial protección por su interés general para la economía.

Con ácido sentido del humor lo expresó con meridiana claridad Andy Warhol en relación a la mentalidad al efecto de la sociedad norteamericana: «Es mucho más americano consumir que pensar».

No es por ello casual que el movimiento cooperativo en sus inicios observara el consumo como uno de los institutos económicos de su interés preferencial, de manera que las Cooperativas de Consumo fueron las primeras organizaciones de consumidores que aparecieron en el mundo, en la Europa de principios del siglo XIX.

Sus viejos objetivos de consecución de la mejor relación entre calidad y precio, la prestación de servicios generales de abastecimiento y la información del consumidor, son hoy los distintivos de todas las grandes compañías de la distribución comercial.

La llamada «planificación consumerista» de Gide y la Escuela de Nimes, presentada como guía del Cooperativismo en el Cuarto Congreso de la Alianza Cooperativa Internacional, celebrado en París en 1889, se basaba en tres etapas sucesivas.

En la primera el movimiento cooperativo mundial fomentaría las cooperativas de consumidores, unidas por medio de grandes centrales mayoristas de compras.

Posteriormente se promoverían cooperativas de productores para la fabricación masiva de artículos, que distribuirían las centrales cooperativas de consumo. Finalmente las cooperativas adquirirían directamente tierras y explotaciones agropecuarias para fomentar el cooperativismo agrario, completando así la participación cooperativista en todos los sectores económicos: primario, industrial y de servicios².

1 Charles Gide: «Les sociétés cooperatives de consommation». Paris, 1904.

2 Sobre la planificación de Gide puede verse a Mario Arango Jaramillo: «Manual de Cooperativismo y Economía Solidaria». Universidad Cooperativa de Colombia. Medellín, 2005 (p. 88). 
Esa planificación debía financieramente apoyarse con el crédito cooperativo, tanto en las ciudades (cajas populares) como en el campo (cajas rurales), para que el movimiento cooperativo no quedara en manos de la financiación capitalista.

En su inicio, la visión cerrada y global del ideario cooperativo proviene del movimiento cristiano cuaquerista ${ }^{3}$ (3), que al modo de la agustiniana "Ciudad de Dios», como las comunidades de ayuda mutua de los primeros cristianos ( por algo se calificó al cooperativismo inicial de «socialismo utópico»), pretendía crear colonias o «repúblicas» cooperativas cerradas ante las maldades del mundo, siguiendo precisamente el modelo de las «Sociedades de Amigos» cuáqueras.

No es casual que el Estatuto de Rochdale, en su preámbulo de «Fines» de la Sociedad, dijera textualmente: «Desde el momento que sea posible, esta sociedad emprenderá la organización de las fuerzas de producción, de la distribución, de la educación y del gobierno, o, dicho en otras palabras, el establecimiento de una colonia que se baste a sí misma y en la que se unirán los intereses, o bien prestará ayuda a otras sociedades para establecer colonias de esa clase» ${ }^{4}$.

Es por ello que Plockboy fue llamado «Patriarca de la Cooperación», siendo su propuesta de «repúblicas cooperativas» (establecida en su ensayo sobre «La Felicidad de los Pobres», de 1659) desarrollada después por el galés Robert Owen ( los «Pueblos de Cooperación») y por el francés Charles Fourier ( los «Falansterios»).

Los estatutos de Rochdale fueron revisados por Charles Howar, discípulo de Owen, que utilizó los de la previa «Sociedad de Socorros para casos de Enfermedades y de Sepelios» de Manchester, aunque también se sostiene que se utilizaron los de "L'Association Chrétiene des Bijoutiers en Doré», constituida en París en 1834, inspirada en el ideario de Jean-Philippe Buchez.

Ciertamente el ideario mutualista, cooperativo y solidario, estaba en la cultura social de aquellos tiempos, de modo que la comunicación entre sus militantes era grande, buscando todos lo que el profesor Del Pino Artacho ${ }^{5}$ ha descrito como la colaboración «...en la configuración de un mundo más solidario y más humano».

3 Javier Divar Garteiz-Aurrecoa: «Peter Cornelius Plockboy y la República Cooperativa». Revesco n. ${ }^{\circ}$ 102. Madrid, 2010, pp. 145 y ss.

4 Estatutos originales de la Cooperativa de los Justos Pioneros de Rochdale, inscritos en Londres el 24 de octubre de 1844, tras su calificación por el «barrister» John Tidd Pratt.

5 Juan del Pino Artacho: "La Economía Social. Unas notas sobre la participación en la empresa y el mercado». N. ${ }^{\circ} 6$ de la Colección Mediterráneo Económico. Edic. Cajamar, S.C. de Crédito, p. 15. 
Debe también quedar claro que los «Probos Pioneros» de Rochdale no eran tan pioneros, puesto que en esa misma población inglesa, del condado de Lancashire, cercana a Manchester, ya había funcionado una fracasada cooperativa de consumo entre 1832 y 1835 (a más de que la primera cooperativa de consumo se había constituido en Brigthon, en 1827, siguiendo la doctrina de William King).

Por eso, lo que Georges Lasserre llamó la «moral social cooperativa» 6 , se basa en los estatutos de los «Probos Pioneros de Rochdale» porque fue una cooperativa de éxito (su modelo se extendió por Inglaterra al punto que al finalizar el siglo, en el año 1900, los socios de cooperativas del «modelo Rochdale» eran ya 1.700.000).

Ciertamente, como se ha dicho muy bien ${ }^{7}$, «los principios cooperativos, al igual que los valores, son formulaciones generales, proclamados desde la Alianza Cooperativa Internacional para todas las cooperativas del mundo. Por consiguiente, su aplicación debe ajustarse a las circunstancias concretas de cada cultura, de cada país».

Y eso porque la delimitación jurídica de las sociedades cooperativas tienen en su causa remota «entornos confusos», como los ha definido Gustavo Portillo 8 , que añade: «El movimiento cooperativo tiene sus fundamentos en ideas que tienen que ver con la solidaridad, la igualdad, la participación, la administración democrática, la honradez, la ausencia de ánimo de lucro, la primacía del trabajo frente al capital».

Precisamente por todo eso la historia de la reforma de los principios cooperativos es muy larga, como magistralmente estudió Mateo Blanco ${ }^{9}$, siendo una constante de los Congresos de la Alianza Cooperativa Internacional (ICA-ACI).

Como doctrina económica la Cooperación se define casi mejor por lo que no es que por lo que es, como opositora al capitalismo, en lo que hoy en día ha dado en Ilamarse Economía Social (o del Tercer Sector o de Interés General).

Ese es precisamente el argumentario que utilizó Carlos Horteserth en su «Carta de la Cooperación», presentada ante la Cámara de los

6 George Lasserre: «El hombre cooperativo». Edic. Universidad Cooperativa de Colombia. Bogotá, 2008, p. 51.

7 Jorge Eliécer Quijano Peñuela y José Mardoqueo Reyes Grass: «Historia y doctrina de la cooperación». Universidad Cooperativa de Colombia. Bogotá, 2004, p. 111.

8 Gustavo Portillo: "Cooperativismo: crisis de valores, crisis de conducta». Rev. Venezolana de Análisis de Coyuntura, vol. V, n. ${ }^{\circ} 2$ (segundo semestre), 1999. Citas en las páginas 94 y 97.

9 Joaquín Mateo Blanco: «Historia de la reforma de los principios cooperativos». Revesco n. ${ }^{\circ}$ 53. Madrid, 1985, pp. 37 a 68. 
Comunes para conseguir su apoyo en beneficio de la justicia distributiva y la participación en la economía. Es la doctrina del No, de la no molestia a los poderes establecidos. Decía Horteserth en ella que la Cooperación:

- No afecta a la fortuna de nadie.

- No trastorna la sociedad.

- No molesta a los hombres de Estado.

- No constituye una sociedad secreta.

- No quiere ninguna violencia.

- No causa ningún desorden.

- No ambiciona honores.

- No reclama favores.

- No pide privilegios.

- No trata con holgazanes.

- No busca ayuda oficial.

- No quiere monopolios.

Dicho de otro modo, la economía de la cooperación no pretende una revolución política, sino sólo hacer compatibles «el materialismo pragmático con el idealismo», como describió el profesor Fairbairn ${ }^{10}$ la evolución del cooperativismo en la provincia canadiense de Saskatchewan.

Aunque esto tampoco sea del todo cierto, ya que el cooperativismo busca superar el capitalismo para democratizar la economía. Por ello se ha dicho que en la evolución del cooperativismo tuvieron «notable influjo ... los anticapitalistas ricardianos ${ }^{11}$.

Pero con sabia humildad, en su origen los fines directos de los cooperativistas eran sólo los de mejorar sus míseras vidas. En los propios Estatutos primitivos de Rochdale se lee que la cooperativa de los Probos Pioneros «... tiene por fines y como planes tomar medidas con vista al interés pecuniario y al mejoramiento de las condiciones sociales y familiares de sus miembros» («Fines», apartado 1.․, párrafo 1. ${ }^{\circ}$ ).

Pero lo cierto es que las cooperativas y cada movimiento cooperativo con su propia adecuación a las circunstancias de su tiempo y de su lugar «... traspasaron la democracia del campo político al

10 Brett Fairbairn: «La provincia cooperativa de Canadá: individualismo y mutualismo en una sociedad de colonos, 1905-2005». Revista Venezolana de Economía Social, año 4, n. ${ }^{\circ}$ 8, segundo semestre de 2004, pp. 72 a 103 (la cita en la p. 80).

11 J.L. Monzón, R. Calvo Ortega, R. Chaves Ávila, I.G. Fajardo, F. Valdés Dal-Re: «Informe para la elaboración de la Ley de Fomento de la Economía Social». Ciriec-España (diciembre de 2009), p. 6. 
económico» ${ }^{12}$, estando en ello precisamente su esencia, en ser la avanzadilla de la democratización de la empresa.

Bien está que la Alianza Cooperativa Internacional, en labor constante de su larga y meritoria trayectoria, vaya delimitando y poniendo al día los principios cooperativos, pero en puridad jurídica estos se reducen a dos: la participación societaria democrática y la cooperativización del beneficio (o excedente), como caracteres societarios.

La democratización societaria impone que la legislación de sociedades cooperativas establezca como derecho, por supuesto, la libertad jurídica de los partícipes (bajas voluntarias) y su integración objetiva (indiscriminación de las altas), así como el voto unipersonal (salvo especiales previsiones legales).

La cooperativización de la aplicación de los resultados económicos exige que la legislación establezca que la detracción de beneficios (retornos) se establezca necesariamente por índices de participación del socio en el objeto societario (nunca a prorrata de su cuota en el capital social, puesto que no es una sociedad capitalista).

Todo lo demás en la delimitación jurídica de las cooperativas no es «fuente de aplicación» de su especializado régimen jurídico, de manera que los enunciados generales en las leyes de cooperativas son sólo pronunciamientos extrajurídicos que hacen referencia a "causas remotas», meramente intencionales y filosóficas, que están fuera del control normativo.

No es adecuado, en buena técnica legislativa cooperativa, hacer referencias generales a «los principios cooperativos» sin identificaciones, dejando su enunciado a indicadores «extralegales», que pueden causar inseguridad jurídica en la práctica, por quedar fuera del ámbito propio del Derecho.

Como ejemplo de ello, la vigente Ley Vasca de Sociedades Cooperativas, del 24 de junio de 1993, que en su artículo 1.1 delimita la cooperativa como «... sociedad que desarrolla una empresa ... observando los principios del cooperativismo...», sin delimitarlos, con lo que se hace insegura su naturaleza jurídica.

Y por si no fuera poco, el número 2 del mismo artículo 1 dice que: «La cooperativa deberá ajustar su estructura y funcionamiento a los principios cooperativos, que serán aplicados en el marco de la presente ley.» Con lo que está dejando claro que esos principios, no determinados legalmente, conforman la naturaleza jurídica societaria.

12 Jorge Orozco Vílchez: «Doctrina Cooperativa: antología». Costa Rica. San José, 1985, p. 43. 
Y todavía más. El número 3 del mismo artículo, con el que concluye el mismo, indica que las actividades económicas y sociales de las cooperativas sólo pueden limitarse por «expresa prohibición legal basada en la incompatibilidad con las exigencias y principios básicos del cooperativismo».

Que esa indeterminación puede provocar inseguridad al afectar a la naturaleza jurídica de la sociedad cooperativa queda clara al terminar el artículo 12 número 3 de la ley impidiendo la libertad de pacto en la escritura pública de constitución si su articulado contradice «los principios configuradores de la sociedad cooperativa».

La Ley General de Cooperativas de España, de 16 de julio de 1999, en referencia a este punto, dice en su artículo 1.1 que la sociedad cooperativa debe tener «estructura y funcionamiento democrático, conforme a los principios formulados por la Alianza Cooperativa Internacional» (citando así un referente de acreditación «extralegal»), aunque añadiendo, "en los términos resultantes de la presente Ley» (siguiendo casi literalmente a la antes citada Ley Vasca de Sociedades Cooperativas).

Más allá, el Reglamento de la UE de Sociedad Cooperativa Europea (SCE), de 12 de julio de 2002, ni siquiera menciona los principios cooperativos, como destaca Josefina Fernández Guadaño, del que dice «... evita la alusión a los principios cooperativos enunciados por la $\mathrm{ACl}$ e incluso entra en contradicción con alguno de ellos» ${ }^{13}$.

\section{En conclusión}

No parece razonable trasladar unos principios históricos de carácter teórico, elaborados por una organización internacional no gubernamental, al ámbito de las aplicaciones jurídicas de la legislación sobre sociedades cooperativas, afectando a su naturaleza jurídica y por ello al contenido de sus propios estatutos sociales.

En beneficio de la seguridad jurídica, los aludidos principios deben reducirse a caracteres legales que delimiten la naturaleza jurídica de las cooperativas como personas jurídicas reconocidas por el Derecho.

Atendiendo a la necesaria concreción legal, esos caracteres deben ser técnicos jurídicos y huir de las imprecisas formulaciones filosóficas, para así delimitar la naturaleza jurídica de las sociedades cooperativas.

13 Josefina Fernández Guadaño: «La desmutualización de la sociedad cooperativa en Europa». Revista Venezolana de Economía Social, año 8, n. ${ }^{\circ} 15$, enero-junio de 2008. Edit. Universidad de Los Andes. 
En concreto, la legislación de sociedades cooperativas, para cumplimentar ese objetivo, sólo debe extenderse a caracterizar la democracia cooperativa y el establecimiento de una participación en los resultados económicos basada en la de los socios en el objeto social, nunca en prorrateos relacionados con las cuotas sobre el capital.

\section{Bibliografía}

Charles GIDE: «Les sociétés cooperatives de consommation». París, 1904.

Mario Arango JaRAmillo: "Manual de Cooperativismo y Economía Solidaria». Universidad Cooperativa de Colombia. Medellín, 2005.

Javier Divar Gartelz-AurreCoA: «Peter Cornelius Plockboy y la República Cooperativa», Revesco, n. ${ }^{\circ}$ 102. Madrid, 2010.

Juan DEL PINO ARTACHO: «La Economía Social. Unas notas sobre la participación en la empresa y el mercado». Colección Mediterráneo Económico, n. ${ }^{\circ} 6$. Cajamar, S.C.C.

George LASSERRE: El hombre cooperativo. Edic. Universidad Cooperativa de Colombia. Bogotá, 2008.

Jorge Eliécer QuiJano Peñuela y José Mardoqueo ReYEs Grass: Historia y doctrina de la cooperación. Universidad Cooperativa de Colombia. Bogotá, 2004.

Gustavo PoRTILlo: "Cooperativismo: crisis de valores, crisis de conducta». Revista Venezolana de Análisis de Coyuntura, vol. V, n. ${ }^{\circ} 2 .{ }^{\circ}{ }^{\circ}$ semestre de 1999.

Joaquín MATEO BLANCO: «Historia de la reforma de los principios cooperativos». Revesco, n. ${ }^{\circ}$ 53. Madrid, 1985.

Brett FAIRBAIRN: «La provincia cooperativa de Canadá: individualismo y mutualismo en una sociedad de colonos, 1905-2005». Revista Venezolana de Economía Social, año 4, n. ${ }^{\circ}$ 8. 2. ${ }^{\circ}$ semestre de 2004.

J.L. Monzón, R. Calvo Ortega, R. Chaves Ávila, I.G. Fajardo, F. Valdés Dal-Re: «Informe para la elaboración de la Ley de Fomento de la Economía Social». Ciriec-España. Diciembre de 2009.

Jorge Orozco Vílchez: Doctrina Cooperativa: antología. San José de Costa Rica, 1985.

Josefina FernÁndez GuAdaño: «La desmutualización de la sociedad cooperativa en Europa». Revista Venezolana de Economía Social, año 8, n. ${ }^{\circ} 15.1$. er se- $^{-}$ mestre. Universidad de los Andes. 2008. 